\title{
sciendo
}

DOI 10.2478/sbe-2019-0023

SBE no. 14(2) 2019

\section{THE CONSUMER OF UNIVERSITY EDUCATIONAL SERVICES - A CENTRAL ELEMENT OF EDUCATIONAL MARKETING}

\author{
DURALIA OANA \\ Lucian Blaga University of Sibiu, Romania
}

\begin{abstract}
:
The marketing of educational services has become both a priority and a challenge, taking into account the technological changes that have arisen from the aspect of the tools and teaching methods used, as well as from the point of view of the requirements on the market manifested by the bearers of labor demand and supply. In addition, the opening and internationalization of these services has led to an increase in competition in this area, which forces universities to attach greater importance to educational marketing activities. From the point of view of the study of the behavior of the consumer of university educational services, the approach is even more challenging as the offer of educational services presupposes the rendering of an inexpensive, unstable, perishable and extremely variable service in terms of diversity, which requires an extremely complex analysis of the variables that influence the behavior of the "consumer" student, as well as from the point of view of the purchasing decision process, as a result of the action of these factors. In this context, the present paper aims to analyze the necessity of applying specific educational marketing tools, methods and techniques, especially of university marketing, not only from the perspective of the promotional component, which has a leading role in this field, but also starting from to the analysis of the peculiarities of the behavior of the consumer of educational services as a beneficiary.
\end{abstract}

Key words: consumer behavior, educational marketing, higher education

\section{Introduction}

The global increase in demand for educational services, especially for those offered in the university system, has led, at national level, to the emergence, on the one hand, of pressure on a higher budget allocation for the education sector, and on the one hand, of the need to adapt the management and marketing policies of universities to an increasingly competitive market, extremely heterogeneous in terms of the educational services offered and with an progressively selective target consumer segment. 
The growing involvement of the private sector in conducting and supporting study programs, the emergence of tuition and budgeted positions, has pushed universities towards a "business" approach both in attracting and managing funds, as well as in terms of aligning the offers to market requirements.

As a result, the use of educational marketing tools and concepts comes to support the efforts of universities in trying to attract new consumer segments, targeting both national and international markets, aiming, as any service provider, at gaining a good position in the educational services market.

Starting from Friedman's (1962) approach, which emphasized the need to use market mechanisms in less "common" sectors, such as education, and continuing with Dill's (1997) approach which highlights that although many of the market-specific instruments cannot be applied in the university sector, the "market-type coordination mechanisms" started to be increasingly used by universities.

Subsequently, Scott et al. (2004) emphasized the fact that "universities now seem to be regarded as technically contrived service organizations that willingly accept whatever values their key stakeholders (notably government and industry) seek to impose".

In line with these views, authors such as Naidoo \& Jamieson in "Empowering participants or corroding learning? Towards a research agenda on the impact of student consumerism in higher education" (2005) pinpointed the fact that "universities that are in the upper levels of the hierarchy with high levels of academic, reputation and financial capital are likely to draw on superior resources to engage in practices aimed at conserving the academic principles of structuring the field of education, thereby maintaining their dominant position".

All in all, it can be said that "in the last twenty years, however, the university has metamorphosed rapidly into a completely different institution - if such a perpetually mobile business-oriented entity may still be called an 'institution'” (Hassan, 2003).

\section{Orienting educational marketing towards the consumer}

The importance of marketing orientation towards the activities carried out by universities has been previously highlighted starting from the characteristics of educational services, from the increase of competition at national level through the emergence of private universities, from the opening and internationalization of university educational services market, all these characteristics being corroborated with a continuously diversifying labor market requirements brought about by the development and penetration of technological innovation in almost all sectors of activity.

First and foremost, the consumer of educational services needs information, which has to be available, up-to-date, accurate, and relevant, so as to help him perceive the quality of an intangible service to be provided.

The provision by universities of what specialized literature describes as "good experience" (Dill \& Soo, 2004), respectively of goods / services which are acquired at a low frequency and whose quality can be appreciated in particular after the consumption of the service, while radically influencing the student's professional future, compels universities to utilize both online and offline channels to transmit information to current and potential 
students, thus meeting their need to have access to tangible information / depictions that ease the perception of the quality of educational services in before the purchase phase.

Another aspect underlining the imperative of the application of educational marketing in the activity of universities can be explained by the notion of efficiency. Universities offer study programs that contribute to the development of lifelong knowledge, skills and abilities that should prove to be "cost-effective" both on a personal and a private level, due to the financial gain generated by professing the studied subject as well as on a social plan, due to the benefits which are added value to the human capital, hence the need of the state to support this sector of activity, through grants (budgeted places, scholarships) awarded to noteworthy students (Brennan \& Shah, 2000).

In the context described above, there is also the notion of university-level competitiveness, based on "brand name" and market reputation and having the capacity to attract more potential students to those universities that consider this added value to the human capital, to the detriment of the universities that only assess and quantify the preexisting knowledge and skills of the consumers of academic educational services. The role of educational marketing in this endeavor is to increase the visibility of the university both at national and international level by properly promoting the study programs so as to successfully attract potential students by highlighting the advantages offered to them during the course of the study program chosen, as well as by presenting the employment and professional opportunities they have upon graduation. In general, it can be appreciated that the main attributes taken into account by the student-consumer of educational services when choosing a university / faculty are: the reputation of the teaching staff, the admission requirements for a specific a study program, the prospects of graduation employment, the material basis and study facilities, the social life associated with the study period, the cost of studies (Dill \& Soo, 2004).

An additional aspect closely correlated with the need to apply marketing in the activity of universities is that related to "temporality" (Maringe \& Gibbs, 2009). Although university studies take place over a period of time, typically over 3-5 years, the effects generated influence the life of the individual with a major impact on the quality of the program. Thus, it is the marketing activity that must facilitate the meeting between the satisfaction of the short-term interests with the long-term interests of the consumer of the university educational services.

The activities associated with university marketing must provide the consumer with the confidence in the services and the university, and this can only be achieved if the information transmitter, in this case the university / faculty is perceived as a strong, attractive and credible source. The idea behind that should be that marketing activity ends at a certain point in time, but the education gained by the student-consumer is lasting, and consequently the student needs to know exactly what he/she is investing in and what results are expected from this effort, in all its aspects (financial, psychological, time-related etc.).

In conclusion, it can be argued that the extension of the role of marketing in the optimal development of the activity of the providers of academic educational services is due to the concurrent action of four categories of factors, namely (Smith et al., 1995): 
$>$ The massification of university education - has arisen as a result of the massive pre-university education, and represents a real challenge for universities in their attempt to add value to the training of students;

$>$ The growth and diversification of institutions providing educational services has led to an increase of the competition in university education, a direct consequence being the existence of several alternatives to the study programs at the students' choice, also materializing in a constant pressure on the universities in trying to find an optimal strategy that meets the expectations of the students but which may, in most cases, be unsubstantiated by competences;

$>$ The increase in heterogeneity in higher education - as a result of the internationalization of university education, students now have the opportunity to train outside the country, the expansion of the Internet giving them the possibility of accessing online study programs;

$>$ The accentuation of competition between universities - is manifested as a result of the action of the above-mentioned factors, which guides the strategic approach of universities towards finding a balance between the orientation towards the student as a service consumer and that specific to the universities as providers of a an added value that is quantifiable in the long-run.

The constant pressure exerted by all these factors has led to the minimization of university autonomy from a certain perspective, with the higher education institution being somewhat "forced" to abandon the choice of the student segment and of the teaching mode, orienting its strategy towards a business, where the university needs to be extremely attentive to market signals and make sustained efforts to remain visible both nationally and internationally.

According to Maringe \& Gibbs (2009), this orientation towards the student as consumer of educational services is based on the following principles:

$>$ The student is not always right but knows his/her role in guiding the activity of the higher education institution, so universities must pay particular attention to the knowledge of the following aspects related to the profile of the educational services consumer:

* Who is this consumer of educational services and which are the demographic, economic, psychographic and behavioral criteria that can be applied in order to optimize the segmentation of the market;

* Knowledge about the current and potential students' opinion vis-à-vis the institution, its educational offer and employment opportunities at graduation;

* Identifying their interest in the knowledge, skills and competences that they intend to acquire during the study programs.

$>$ Students' expectations regarding the quality of the educational services to be provided must be properly managed so that there is fair exchange on both sides without affecting the program's standards or the reputation of the institution;

$>$ Student satisfaction as a consumer of educational services should be at the heart of the activities initiated by the university / faculty, by their exposure to diversified teaching methods, contact with enthusiastic trainers who are passionate about their 
work, as well as the creation of a rigorous but objective assessment framework, all of which are the essential conditions for obtaining a favorable attitude on the students' part;

$>$ The orientation of the educational institution towards the consumer should be seen as a long-term approach, which means removing the barriers that interfere with the student-university-labor market relationship and finding a marketing approach that corresponds to the image of the institution on the market.

\section{Behavior of the consumer of educational services - European perspective}

The consumer of educational services can be seen as a "double" consumer. On the one hand, they are the beneficiary of an educational service, and, on the other, they are the consumer of tangible goods resulting from the provision of the educational service itself, respectively the user of the technical-material base of the training institution (Paiva, 2012).

As mentioned above, the higher education institution may opt for targeting a segment of consumer-students that can be segmented according to socio-demographic, economic, psycho- graphical and behavioral criteria, by offering either study programs in strictly specialized fields or training courses in areas with wider specializations.

A profile of the student as a consumer of university education services has not been fully outlined so far, and this is a very complex issue, since the influencing factors are extremely difficult to analyze, being continuously fluid and diverse.

Thus, with respect to directly observable factors, the issues are relatively easy to underline and analyze, the socio-demographic, economic and marketing mix factors being most often direct determinants of the purchasing behavior of educational services. With regard to factors with deducted influence, they may be rather difficult to analyze because, for example, the action of endogenous factors, especially the motivation to follow a faculty, is no longer strong enough, as compared to the pressure recorded in the close (family, friends, colleagues) and reference groups (different professional groups, successful people etc.).

Alfinito \& Torres (2008) are two of the specialists who have tried to outline a consumer profile in higher education, highlighting three categories of consumers of academic educational services, namely:

$>$ The traditional student, who is $18-24$ years old, a high school graduate who does not work, and focuses exclusively on completing studies;

$>$ The non-traditional student, who is over 25 years of age, has a job and most of the times a family, and who decides to continue his/her studies, forced by the pressure of securing the job or by aspiration to a better position within the organization;

> The "first generation" student, who is usually pushed by parents to attend a college, parents who are not graduates of higher education, but who thus fulfill a dream through their children.

It is worth noting that universities are increasingly seeking to attract students from outside the country, offering them a range of study facilities, such as scholarships, campus accommodation facilities etc. Practically, the globalization and internationalization of 
university education has led to unprecedented student mobility, and this phenomenon is particularly visible from East to West.

Starting from this phenomenon, a series of papers elaborated in recent years have sought to analyze this phenomenon of student mobility in terms of educational services, one of the most relevant ones being published by World Education Services (2012), which highlights no less than four categories of consumers of educational services choosing to study abroad, namely:

$>$ Explorers: low academic preparedness, high financial resources;

$>$ Highfliers: high academic preparedness, high financial resources;

> Strugglers: low academic preparedness, low financial resources;

$>$ Strivers: high academic preparedness, low financial resources.

Another very relevant study was published by the European Commission in its Flasheurobarometer report no. 466 of April 2018, which focused on presenting relevant aspects of the European education area. Education reforms have been one of the European Commission's objectives through the Europe 2020 strategy (www.europa.eu)

Taking as a starting point this phenomenon of student mobility at European level, the present study aims to highlight the perception of young Europeans regarding:

$>$ teaching / learning methods encountered in European universities;

$>$ the importance and benefits of studying across borders for European students;

$>$ the need to know an international language that facilitates access the European universities' study programs and not only.

Thus, the analysis of the existing data reveals that among the young Europeans aged 15-30 years interviewed, $90 \%$ said it was important to have a study opportunity abroad, the countries with the highest percentage being Italy (78\%), Cyprus (72\%) and Portugal (71\%), with Bulgaria (28\%), Denmark (27\%) and Sweden (2. 3\%) at the opposing end.

At the level of Romania, the analyzed data reveals that $47 \%$ of the respondents stated that it is very important to have an opportunity to study abroad, $43 \%$ of the interviewed young people having a favorable opinion and only $9 \%$ perceiving this as irrelevant (Fig.1.- The importance of having a study opportunity abroad).

Fig.1. The importance of having a study opportunity abroad

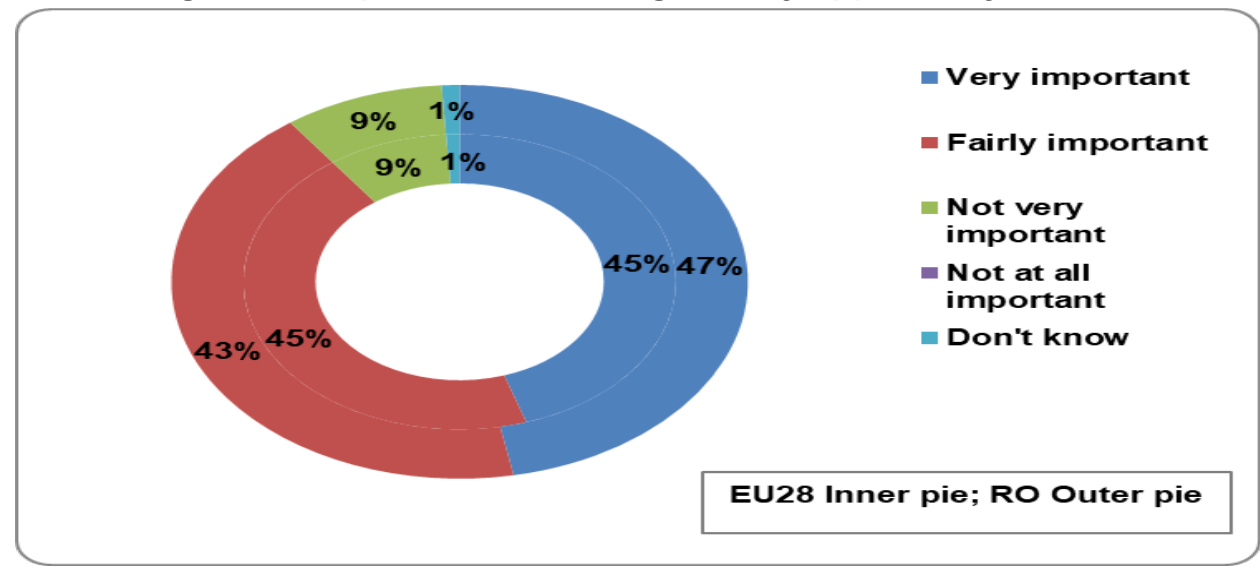

Source: European Commission, Flasheurobarometer no. 466/April 2018, p.6(www.europa.eu) 
Although young Europeans have a favorable perception of the existence of opportunities to continue their studies abroad, only $26 \%$ of the EU28 respondents have said they have benefited from such experience, with the countries with the highest percentage of favorable responses to that variable being Luxembourg (61\%), Latvia (42\%), Cyprus (39\%), Bulgaria $(37 \%)$, the lowest percentage being recorded in Greece $(17 \%)$, Malta (15\%), Portugal (13\%) (Figure 2 - Distribution of responses of young Europeans who have had a study abroad experience).

Fig.2.- Distribution of responses of young Europeans who have had a study abroad experience

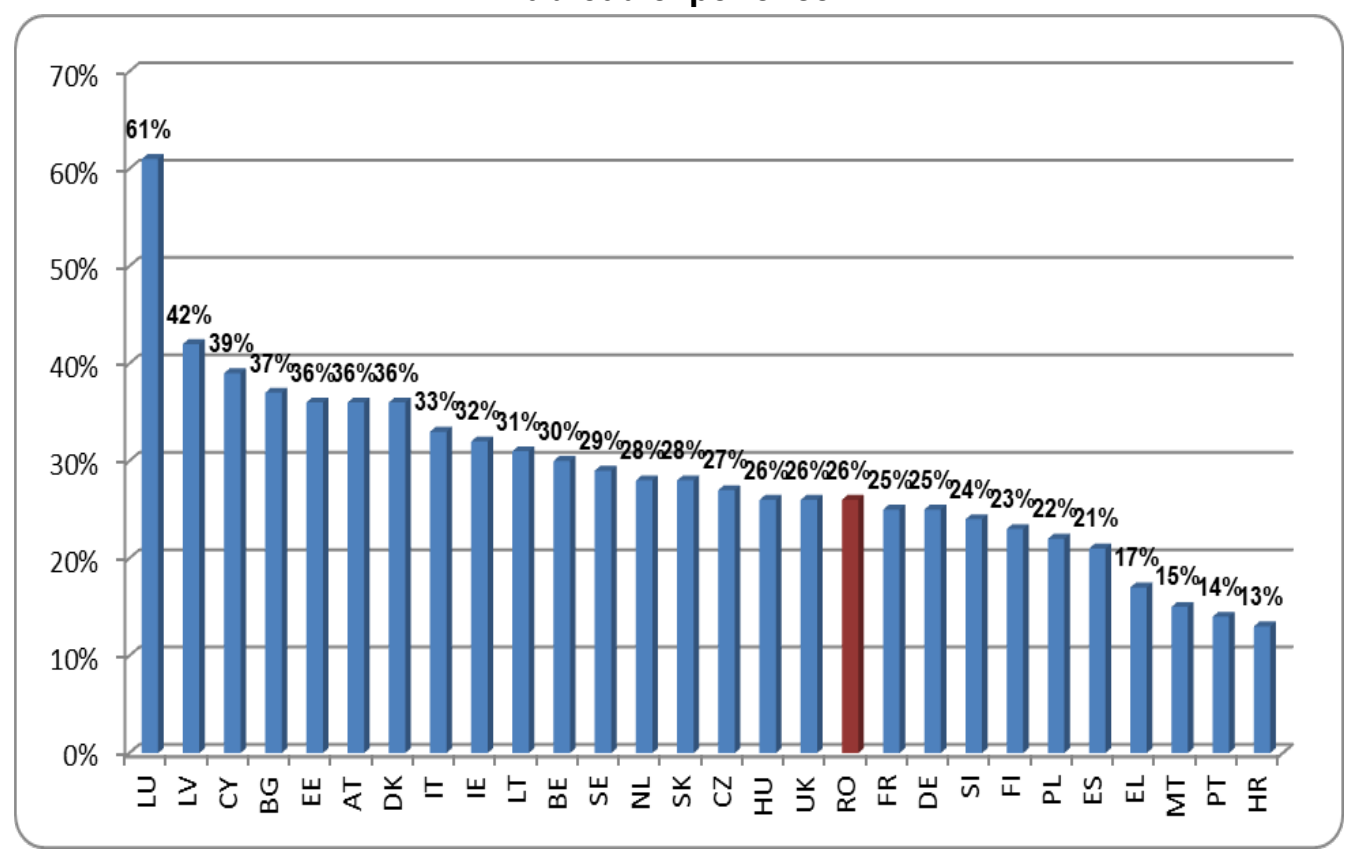

Source: European Commission, Flasheurobarometer no. 466/April 2018, p.9(www.europa.eu)

In what regards the reasons that prevented them from attending a study program abroad, respondents who did not access one of the study mobilities abroad indicated in descending order the following aspects: the absence of such an opportunity, family, personal reasons or lack of financial resources, lack of information on applying for such a program, lack of knowledge of foreign languages, the fear that such a program would prove too difficult. (Fig.3 - The main reasons that prevented young Europeans from accessing a study program abroad - multiple choice answers) 
Fig.3.- The main reasons that prevented young Europeans from accessing a study program abroad - multiple choice answers

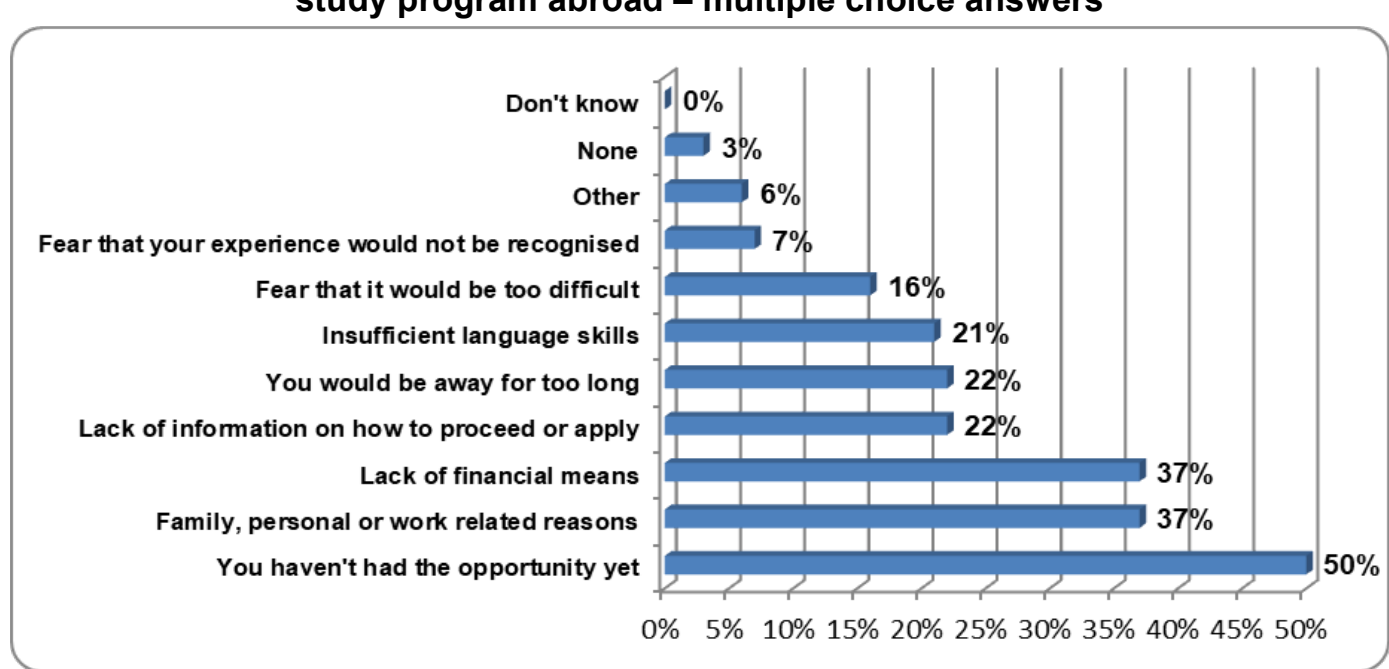

\section{Source: European Commission, Flasheurobarometer no. 466/April 2018,} p.17(www.europa.eu)

Regarding the benefits perceived by young Europeans as a result of the existence of an opportunity to study abroad, over $50 \%$ of those who have accessed study mobilities outside the country have indicated that the advantages of improving language skills and knowledge of different cultures, the possibility of becoming more independent and of meeting new people (36\%), increased opportunities to get a better job $(24 \%)$, and the development of new skills (22\%). (Figure 4 - Main benefits perceived by young Europeans who have studied abroad -3 answers max.)

Fig.4. - Main benefits perceived by young Europeans who have studied abroad 3 answers max.

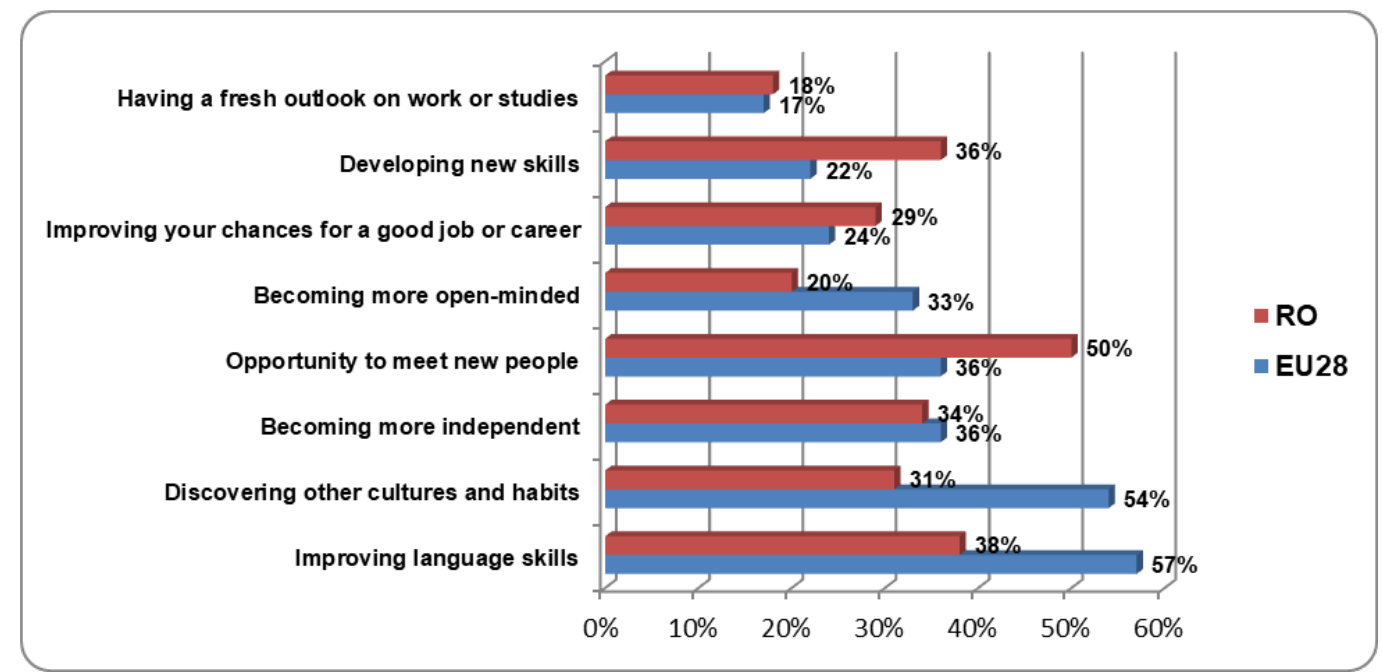

Source: European Commission, Flasheurobarometer no. 466/April 2018, p.13(www.europa.eu) 
Another very interesting variable targeted by the EU28 research has revealed that an overwhelming proportion of young Europeans, namely $91 \%$, indicated that the existence of an automatic system for recognizing credits and certifications obtained by accessing some programs study abroad was an important aspect (Fig.5.- The importance of a unitary automated system of recognition of credits and certifications obtained abroad)

Fig.5.- The importance of a unitary automated system of recognition of credits and certifications obtained abroad

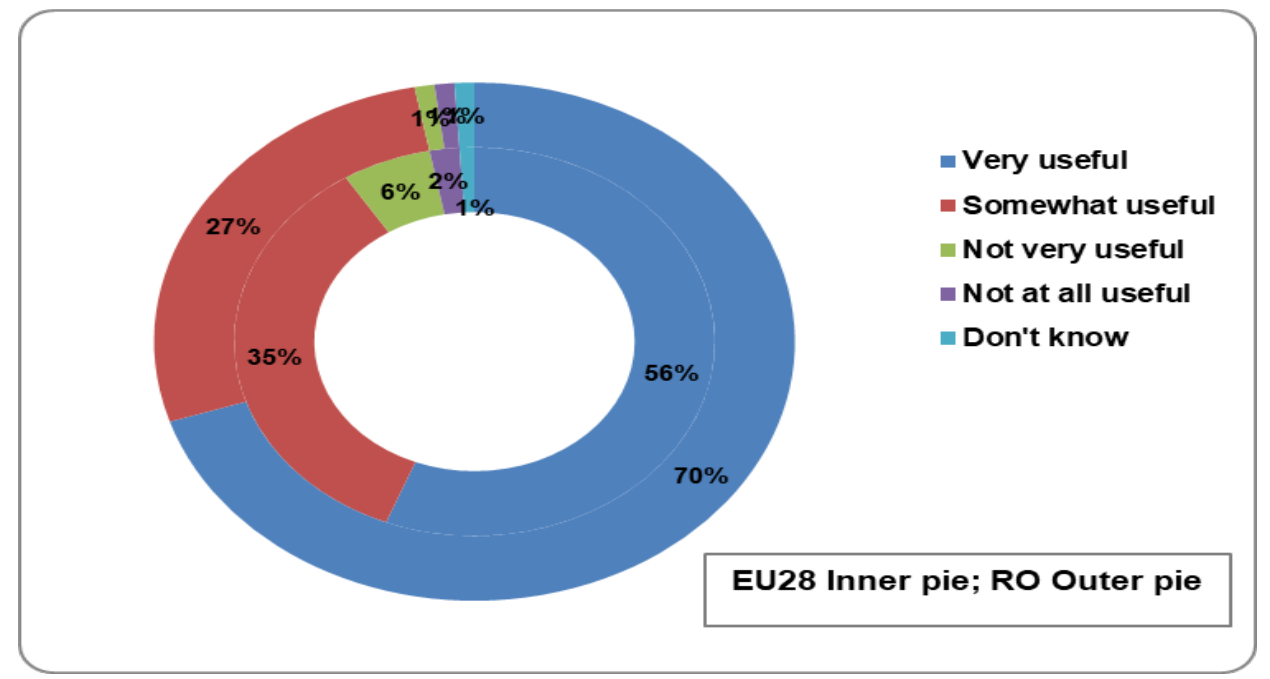

Source: European Commission, Flasheurobarometer no. 466/April 2018, p.25(www.europa.eu)

\section{Conclusions}

As we can see, the extent to which the state is involved in supporting university education through the regulations and subsidies offered, as well as the level of competition in higher education, varies greatly from one country to another. This greatly widens the way of applying and using the specific educational marketing tools. Finding a model to meet the interests of all parties involved in this endeavor is quite a difficult task, due to several variables: the student who wishes to complete his/her studies in order to find a better job; the state that expects the graduate student to add value to the labor market, thus fulfilling social objectives; the university, which is trying to cope with the phenomenon of massification and internationalization of university education, aiming to increase its visibility in order to attract potential students. But the fact is that the orientation of the university marketing activity towards the business model, which puts the student as a of consumer educational services at the forefront, but does not diminish the social role that the university has as a labor-creating institution, which provides knowledge, ideas, and thus changing behaviors by offering models at the social level, is a necessity which is becoming increasingly stringent both at national and international level. 


\section{References}

Alfinito\&Torres(2008) In: Consumer Educational Behavior: Their Profile and the Purchase Decision Process, Alessandra Daiana Schinaider, Paloma de Mattos Fagundes, Anelise Daniela Schinaider, Future Studies Research Journal ISSN 2175-5825 SÃO PAULO, V.8, N.2, P. 149 - 170, ABR./AGO 2016

Brennan, J. and T. Shah.(2000) Managing Quality in Higher Education: An International Perspective on Institutional Assessment and Change. Buckingham, UK: OECD, SRHE and Open University Press;

Dill, D.D. (1998) Evaluating the 'Evaluative State': Implications for Research in Higher Education. European Journal of Education 33.2 , p. 361-377. In: Markets In Higher Education Rhetoric or Reality?.Published by Kluwer Academic Publishers;

Dill, D.D. and M. Soo. (2003) A League Table of League Tables: A Cross-National Analysis of University Ranking Systems. Paper presented at the Conference of the International Network of Quality Assurance Agencies In Higher Education (INQAAHE), Dublin, Ireland, 17 April. In Markets In Higher Education Rhetoric or Reality?. Published by Kluwer Academic Publishers;

Friedman, M. (1962) Capitalism and Freedom. Chicago: University of Chicago Press;

Hassan, R. (2003) The Chronoscopic Society: Globalization, Time and Knowledge in the Network Economy. Oxford: Peter Lang;

Maringe, F. \&Gibbs,P. (2009) Marketing Higher Education Theory and Practice. Open University Press;

Naidoo, R. and Jamieson, I. (2005) Empowering participants or corroding learning? Towards a research agenda on the impact of student consumerism in higher education. Journal of Education Policy, 20(3), p. 267-81;

Paiva, R. (2012) Gestão de marketing educacional. Curitiba: IESDE Brasil. In: Consumer Educational Behavior: Their Profile and the Purchase Decision Process, Alessandra Daiana Schinaider, Paloma de Mattos Fagundes, Anelise Daniela Schinaider, Future Studies Research Journal ISSN 2175-5825 SÃO PAULO, V.8, N.2, P. 149 - 170, ABR./AGO 2016;

Scott, D., Brown, A., Lunt, I. and Thorne, L. (2004) Professional Doctorates: Integrating Professional and Academic Knowledge. Milton Keynes: Open University Press;

Smith, D., Scott, P. and Lynch, J. (1995) The Role of Marketing in the University and College Sector. Leeds: Heist Publication

WES Research \& Advisory Services www.wes.org/RAS. (2012) Not All International Students Are the Same: Understanding Segments, Mapping Behavior. Choudaha, Rahul \& Orosz, Kata \& Chang, https://www.researchgate.net/publication/255857496_Not_All_International_Students_are_t he_Same_Understanding_Segments_Mapping_Behavior

http://www.europa.eu , SpecialEurobarometer no.466, last accessed 2019/02/20 